\title{
Involvement in and Views on Social Responsibility of Gauteng Members of the South African Society of Physiotherapy: A Cross-sectional Survey
}

\begin{abstract}
How do physiotherapists in Gauteng Province, who are members of the South African Society of Physiotherapy (SASP), view social responsibility?

A cross-sectional survey was conducted after ethics approval. All 1098 Gauteng members of the SASP were invited via a thirdparty e-mail to reach the a priori minimum sample size of 97 . The web-based questionnaire was developed from literature, an earlier SASP survey and a position paper of the American Physical Therapy Association (APTA). Five experts validated the instrument.
\end{abstract}

The Likert scale scores indicating agreement with indicators of social responsibility were totalled to form a composite social responsibility score. The chi-square test for independence was used to determine associations between the categorised composite social responsibility score and categorical variables. Mean difference of continuous variables between the categorised core for two groups were tested using the two-sample t-test. All variables with a P-value less than 0.05 were included in the logistic regression analysis to investigate predictors of the necessity of social responsibility.

The survey was completed by 163 participants. Of the sample, 96.9\% viewed social responsibility as important. Subjects agreed most with "advocating for the health needs of society" (74,2\%) and the least with "political activism" (6.1\%). Compulsory community service positively influenced $74.6 \%$.

Most physiotherapists in the study viewed social responsibility as important and were involved in volunteering. There is scope to broaden the understanding among physiotherapists of what social responsibility entails.

KEY WORDS: PHYSIOTHERAPY, SOCIAL RESPONSIBILITY, OBLIGATIONS TO SOCIETY, ETHICAL ISSUES, E-SURVEY

\section{INTRODUCTION}

Society grants professionals autonomy in decision-making and self-regulation. Society also recognises and accords physiotherapists, as other health professionals, "a special social, moral, and political status as a profession" (Dharamsi et al. 2007, p 1,591). In turn for these societal benefits, professionals have an obligation towards the bet-

Corresponding Author:

Karien Mostert-Wentzel

PO Box 223, Newlands,

Pretoria 0049

South Africa

E-mail: karien.mostert@up.ac.za terment of society. The duty towards social responsible practices is especially topical in a country like South Africa where training in health-care professions is subsidised by government. In fact, physiotherapists do not only have a responsibility towards themselves and their patients, but also to the broader community to meet society's present and future needs (Fricke 2005). In light of tensions within social responsibility - e.g. balancing monetary gain to make a living, with addressing the needs of vulnerable groups in society - do individual physiotherapists support the notion of social responsibility?

Three common themes about social responsibility were found. These themes are, first, that social responsibility is a basic concern for what is right regarding social and ethical issues (Witt and Silver 1994). Second, social responsibility is a commitment to the pursuit and achievement of a valued end, e.g. human health and welfare (Weed and Mckeown 2003). Third, social responsibility is "the promotion of a mutual trust between the profession and the larger public that necessitates responding to societal needs for health and wellness." (American Physiotherapy Association (APTA) 2004, p. 4).

Social justice - addressing inequities in health care - is fundamental in the drive to the revitalisation of primary health care services (Commission on 
Social Determinants of Health (CSDH) 2008), as well as for broader development (United Nations Department of Education and Social Affairs 2005). Inequalities include those between the developed and the upcoming world, between rural and urban areas, between the poor and the privileged, between females and males, and also between those with disabilities and those without (World Health Organization (WHO) 2008).

From before 2003 the South African Society of Physiotherapy (SASP) took a lead at national level to actively promote the initiative that physiotherapists, along with other cadres of health workers, complete a compulsory service year in the public sector after graduation. This policy initiative directly aims to improve access to health care. In addition, the SASP conducted a survey in 2008 on social responsibility (South African Society of Physiotherapy 2009). It investigated the nature, extent and settings of voluntary services offered by its members. Although the recruitment rate of the survey was low, the findings indicated that the majority of those who responded to the survey were willingly undertaking services in communities.

The views of Gauteng physiotherapists on the elements of social responsibility as advocated by APTA have not been determined, as far as the researchers could establish. This article describes a study to determine these views of Gauteng members of the South African Society of Physiotherapy, as well as practices showing social responsible behaviour. Findings from this study could serve as a reference point for the further evolution of socially responsible physiotherapy practice as part of ethical health care in the province.

\section{METHODS}

\section{Study design and ethics clearance}

This quantitative web-based crosssectional survey received approval from the Faculty of Health Sciences' Ethics Committee, University of Pretoria (UP) (Reference S36/2010).

\section{Study population and sampling}

Of the 5410 physiotherapists registered with the Health Professions Council of South Africa (HPCSA), 1926 had addresses in Gauteng Province. Of these 1098 were members of the SASP and all were invited to participate. Logistically a focus on only one area of South Africa was feasible. Gauteng was appropriate as it has the greatest concentration of physiotherapists compared to other provinces.

\section{Instrumentation}

The researchers compiled the questionnaire from a conceptual framework developed from a literature review, incorporating elements from the SASP survey and APTA indicators of social responsibility (APTA 2004). The questionnaire had three sections: Demographics, Views on Social Responsibility, and Involvement in Volunteer Work.

A multiple-choice question that indicated clearly that more than one option could be selected, tested the subjects' definition of social responsibility. Fivescale Likert-type questions assessed subjects' views on the necessity of social responsibility, the influence of the compulsory community service year on these views, and the level of agreement with statements about social responsibility. Various aspects of subjects' involvement in voluntary services, practices reflecting one aspect of social responsibility, were also asked about. A senior teacher of Afrikaans Language translated the questionnaire into Afrikaans from English. In turn, a teacher of English Language translated the Afrikans questions back into English to ensure that the original meaning was kept.

The questionnaire was administered using a web-based survey tool, SurveyMonkey. The survey started with information about the study so that subjects could consent to participate or not. The survey's 25 questions were presented over six screens. None of the questions were mandatory and participants could exit the survey at any point. Subjects were routed to different questions in accordance with their responses.
Academics from five universities, known to the researchers, who were knowledgeable about physiotherapy, health sciences education (an education consultant and fellow of the Southern African Faimer Regional Institute (SAFRI)), community engagement (first author of a book on service-learning) and/or questionnaire development validated (academic with a $\mathrm{PhD}$ ), scrutined a version of the survey that was e-mailed to them. One of the reviewers commented that volunteering received too much attention. This section was, however, kept, as it was the part from the earlier SASP survey. Five physiotherapists from provinces other than Gauteng piloted the survey. They understood the questions and did not experience technical problems like difficulty logging in to the survey system.

\section{Data collection}

The link to the survey was provided only to members of the SASP in Gauteng Province. The survey option that prevented the capturing of respondents' IP addresses ${ }^{1}$ was used to ensure anonymity.

To optimise the response rate an e-mail was sent as a reminder to all participants two weeks after the initial one (Fan and Yam 2010). Opportunity to participate was allowed for two more weeks. The survey was therefore accessible for four weeks in total.

\section{Data capturing and analysis}

Results captured in SurveyMonkey were exported to Microsoft Office Excel 2007 and imported to STATA 11 for analysis. Descriptive statistics consisted of frequency tables for categorical variables and means and ranges for continuous variables. The Likert scale scores that assessed agreement with the indicators of social responsibility were totalled to form a composite social responsibility score. Higher composite scores indicated higher levels of agreement with the indicators of social responsibility. The composite score was divided into two subcategories, with score less than 20 indicating low level of agreement and the score above 
20 indicating high level of agreement. The chi-square test was used to determine associations between the composite score groups and categorical variables. Mean differences of continuous variables for two groups were tested using the twosample t-test. All variables with a $P$ value of less than 0.05 were included in the logistic regression analysis to investigate predictors of a high level of agreement with the indicators of social responsibility.

\section{RESULTS}

\section{Characteristics of the sample}

The recruitment rate was $20.1 \%$ as 221 of the 1926 members of the Gauteng branch of the SASP viewed the first page of the survey. Of these, $163(73.8 \%)$ completed the questionnaire. Table 1 shows the demographic profile of the sample. The majority were females accounting for $92 \%$. Most participants, $127(77.9 \%)$, had a Bachelor's degree as their highest qualification. The average age was 38 years, ranging from 23 to 72 years. The number of years participants have been practising as physiotherapists ranged from less than one year to 51 years with an average of 14 years. Different settings where physiotherapists work included private practice, private hospitals, state hospitals, rehabilitation centres, sports centres, community projects and other work settings. Of the participants, $63.8 \%$ indicated that they worked in only one type of setting, and $28.2 \%$ worked in two settings.

\section{Views on social responsibility}

The results showed a mixed response about the definition of social responsibility (Table 2$)$. Only 17 (10.4\%) chose all three of the descriptions of social responsibility:

(1) A concept which is based on a basic concern for what is right regarding social and ethical issues,

(2) The promotion of a mutual trust between a profession and the larger public or society that necessitates responding to societal needs,

(3) A duty owed to the public/society to further human welfare (although it is not a duty to fully meet community standards or the expectation of society).
Table 1: Characteristics of the sample $(\mathrm{N}=163)$

\begin{tabular}{|l|r|}
\hline Gender & Frequency (\%) \\
\hline Male & $13(8.0)$ \\
Female & $150(92.0)$ \\
\hline Highest qualification & $15(9.2)$ \\
\hline Certificate or Diploma & $127(77.9)$ \\
Bachelor degree & $21(12.9)$ \\
\hline Master's degree or PhD & $104(63.8)$ \\
\hline Number of settings worked in & $46(28.2)$ \\
\hline 1 setting & $13(8.0)$ \\
\hline 2 settings & \\
\hline 3+ settings & $92(58.2$ \\
\hline Compulsory community service year $(\mathbf{n}=158)$ & $61(38.6)$ \\
\hline Did not have one & $5(3.2$ \\
\hline Yes & \\
\hline Currently busy with it & \\
\hline
\end{tabular}

Table 2: Views on Social Responsibility $(\mathrm{N}=163)$

\begin{tabular}{|c|c|}
\hline & Frequency (\%) \\
\hline \multicolumn{2}{|c|}{ Definition of social responsibility ${ }^{a}$} \\
\hline Definition 1 correct & $31(19.0$ \\
\hline Definition 2 correct & 27 (16.6) \\
\hline Definition 3 correct & $24(14.7)$ \\
\hline Definitions 1,2 \& 3 correct & $17(10.4)$ \\
\hline Definitions $1 \& 2$ correct & $32(19.6)$ \\
\hline Definitions $1 \& 3$ correct & $19(11.7)$ \\
\hline Definitions 2 \& 3 correct & $12(7.4)$ \\
\hline No definition correct & $1(0.6)$ \\
\hline \multicolumn{2}{|c|}{ Necessity of socially responsibility } \\
\hline Yes & $110(67.5)$ \\
\hline Most of the time & $35(21.4)$ \\
\hline Some of the time & $18(11.0)$ \\
\hline \multicolumn{2}{|c|}{$\begin{array}{l}\text { Need for social responsibility towards the profession } \\
(n=161)\end{array}$} \\
\hline Yes & $156(96.9)$ \\
\hline No & $5(3.1)$ \\
\hline \multicolumn{2}{|c|}{$\begin{array}{l}\text { Influence of community service year on views about } \\
\text { the value of social responsibility ( } n=59)\end{array}$} \\
\hline Decreased & $5(8.5)$ \\
\hline Did not influence my opinion & $10(17.0)$ \\
\hline Increased & $44(74.6)$ \\
\hline
\end{tabular}

a Subjects could select more than one option 
Table 3. Level of Agreement with the APTA Indicators of Social Responsibility tested on a Likert Scale (N=163)

\begin{tabular}{|c|c|c|c|c|}
\hline \multirow[t]{2}{*}{ Indicator } & \multicolumn{3}{|c|}{$\begin{array}{l}\text { Agreement with each statement } \\
\text { (Row \%) } \\
\text { Completeness rate (CR) })^{\mathrm{a}}\end{array}$} & \multirow[t]{2}{*}{$\begin{array}{l}\text { Frequency } \\
\text { (Row \%) } \\
\text { CR }^{\mathrm{a}}\end{array}$} \\
\hline & $\begin{array}{c}\text { Rarely to } \\
\text { never }\end{array}$ & Occasionally & $\begin{array}{l}\text { Sometimes } \\
\text { to always }\end{array}$ & \\
\hline $\begin{array}{l}\text { Advocating for the health and wellness needs of society including } \\
\text { access to health care and physical therapy services }\end{array}$ & $0(0.0)$ & $10(7.6)$ & $\begin{array}{l}121(92.4) \\
74.2\end{array}$ & $\begin{array}{l}131(100) \\
80.4\end{array}$ \\
\hline $\begin{array}{l}\text { Participating in collaborative relationships with other health } \\
\text { practitioners and the public at large }\end{array}$ & $2(1.6)$ & $9(7.2)$ & $\begin{array}{l}114(91.2) \\
69.9\end{array}$ & $\begin{array}{l}125(100) \\
76.7\end{array}$ \\
\hline $\begin{array}{l}\text { Ensuring that existing social policy is in the best interest of the } \\
\text { patients/clients }\end{array}$ & $4(3.4)$ & $7(5.8)$ & $\begin{array}{l}109(90.8) \\
66.9\end{array}$ & $\begin{array}{l}120(100) \\
73.7\end{array}$ \\
\hline $\begin{array}{l}\text { Promoting social policy that function, health, and wellness needs } \\
\text { of patients/clients }\end{array}$ & $3(2.8)$ & $10(9.3)$ & $\begin{array}{l}94(87.9) \\
57.7\end{array}$ & $\begin{array}{l}107(100) \\
65.6\end{array}$ \\
\hline $\begin{array}{l}\text { Understanding of current community wide, nation wide and } \\
\text { world wide issues and how they impact society's health and } \\
\text { well-being and the deliverance of physical therapy }\end{array}$ & $7(5.9)$ & $16(13.4)$ & $\begin{array}{l}96(80.7) \\
58.9\end{array}$ & $\begin{array}{l}119(100) \\
73.9\end{array}$ \\
\hline $\begin{array}{l}\text { Advocating for changes in laws, regulations, standards and } \\
\text { guidelines that affect physical therapist service provision }\end{array}$ & $8(6.9)$ & $19(16.4)$ & $\begin{array}{l}89(76.7) \\
54.6\end{array}$ & $\begin{array}{l}116(100) \\
71.2\end{array}$ \\
\hline $\begin{array}{l}\text { Promoting cultural competence within the profession and the } \\
\text { larger public }\end{array}$ & $11(8.9)$ & $19(15.3)$ & $\begin{array}{l}94(75.8) \\
57.7\end{array}$ & $\begin{array}{l}124(100) \\
76.1\end{array}$ \\
\hline $\begin{array}{l}\text { Ensuring the blending of social justice and economic efficiency } \\
\text { of services }\end{array}$ & $16(12.0)$ & $25(18.8)$ & $\begin{array}{l}92(69.2) \\
56.6\end{array}$ & $\begin{array}{l}133(100) \\
81.6\end{array}$ \\
\hline Promoting community volunteerism & $14(11.7)$ & $28(23.3)$ & $\begin{array}{l}78(65.0) \\
47.9\end{array}$ & $\begin{array}{l}120(100) \\
73.6\end{array}$ \\
\hline Participating in achievement of social health goals & $13(11.2)$ & $27(23.3)$ & $\begin{array}{l}76(65.5) \\
46.6\end{array}$ & $\begin{array}{l}116(100) \\
71.2\end{array}$ \\
\hline Providing leadership in the community & $13(10.6)$ & $35(28.7)$ & $\begin{array}{l}74(60.7) \\
45.4\end{array}$ & $\begin{array}{l}122(100) \\
74.8\end{array}$ \\
\hline Participating in political activism & $\begin{array}{l}90(66.7) \\
55.2\end{array}$ & $35(25.9)$ & $\begin{array}{l}10(7.4) \\
6.1\end{array}$ & $\begin{array}{l}135(100) \\
82.8\end{array}$ \\
\hline
\end{tabular}

${ }^{a}$ Completeness rate $=$ proportion of the total sample who answered this question

The majority $(96.9 \%)$ viewed social responsibility as a necessity. Of the 61 (38.6\%) subjects who had completed a compulsory community service year, $44(74.6 \%)$ answered that the year had a positive influence on their view of the value of social responsibility.

Table 3 gives the findings of the level of agreement with each of the APTA indicators of social responsibility. The majority of the respondents agreed with most of the indicators. Subjects agreed mostly with "advocating for the health needs of society" (74,2\%). However, less than $50 \%$ agreed that physiotherapists have a role in "promoting community volunteerism," "participating in the achievement of social health goals" and "providing leadership in the community." Only $6.1 \%$ agreed that physiotherapists should "sometimes to always" "participate in political activism."

Table 4: Univariate Predictors of Agreement with the Indicators of Social Responsibility

\begin{tabular}{|l|l|}
\hline Variable & P value \\
\hline Gender & 0.70 \\
\hline Age & $0.05^{\mathrm{a}}$ \\
\hline Highest qualification & 0.51 \\
\hline Number of settings working in & 0.71 \\
\hline Years in practice & 0.07 \\
\hline Necessity of social responsibility & 0.57 \\
\hline Compulsory community service year & 0.48 \\
\hline
\end{tabular}

a Significant at $P \leq 0.05$

\section{Relationships between variables and the composite social responsibility score}

Table 4 shows the univariate predictors of agreement with indicators of social responsibility. The mean age for physiotherapists with low social responsibility scores was 4.1 years greater than for those with high scores, and this difference was significant ( $\mathrm{p}=0.05$ ). Since the other variables were not significantly related, only age was included in the logistic regression. Results showed that for a one year increase in age, there is a $3 \%$ increase in the odds of having a low social responsibility score [odds ratio $=1.03 ; 95 \%$ confidence interval $(1 ; 1.06)]$. 


\section{Involvement in voluntary work}

The majority of subjects, 119 (77\%) were involved in voluntary services, and $89.1 \%$ found their involvement rewarding. Of the sample, 49, $(41.5 \%)$ spent between zero and three hours per months in voluntary work, and $32.5 \%$ stated the cost of between R0 and R249 to carry out voluntary work. Table 5 shows the factors that were considered for involvement in volunteering.

Of the $35(23 \%)$ who were not involved in voluntary services, 16 indicated that they would like to volunteer. According to two respondents, voluntary service does not fall in the scope of physiotherapy practice. One said that it was too time-consuming; another that enough voluntary services were offered by others, and another was involved in charity work not related to the profession.

The settings where voluntary services were offered can be seen in Table 6. Of the participants, $58.5 \%$ were involved in one type of voluntary work, while 26.3 offered voluntary services in two different settings. The settings where physiotherapists offered voluntary services were spread across different areas, with $26.1 \%$ offering services at schools and $23.5 \%$ at sports clubs or sports events.

\section{DISCUSSION}

The purpose of this study was to measure Gauteng SASP members' views on and involvement in social responsibility. The majority were in agreement with indicators of social responsibility, and were involved in volunteering.

The e-survey recruitment rate (20.9\%) was slightly higher than in the 2008 SASP survey $(12,9 \%)$. A larger proportion of the current study respondents completed this study $(73.8 \%$ versus the SASP's 54.2\%). The demographic profile of the sample is in agreement with the province's physiotherapy population in terms of gender. (Eleven per cent of the Gauteng Province SASP members are male and eight per cent in this study.) Information on other demographic variables of the Gauteng population could not be obtained.

The study confirms the general findings of the 2008 SASP survey as two thirds identified social responsibility as important, and even a necessity. Dharamasi (2007) had similar findings.
Table 5. Involvement in Voluntary Services $(\mathrm{N}=163)$

\begin{tabular}{|l|r|}
\hline & $\mathbf{n}(\%)$ \\
\hline Offer voluntary services (n=154) & $119(77.3)$ \\
\hline Yes & $35(22.7)$ \\
\hline Hours spent on voluntary work (n=118) & \multicolumn{1}{|c|}{} \\
\hline $0-3$ & $49(41.5)$ \\
\hline $4-7$ & $19(34.8)$ \\
\hline $8-11$ & $19(16.1)$ \\
\hline 12 and more & $9(7.6)$ \\
\hline Cost per month to carry out voluntary work in South African Rand (n=114) \\
\hline $0-249$ & $37(32.5)$ \\
\hline $250-499$ & $13(11.4)$ \\
\hline $500-749$ & $18(15.8)$ \\
\hline $750-999$ & $14(12.3)$ \\
\hline $1000-1249$ & $10(8.8)$ \\
\hline $1250-1499$ & $5(4.4)$ \\
\hline $1750-1999$ & $5(4.4)$ \\
\hline 2000 and more & $12(10.5)$ \\
\hline Volunteering personally rewarding (n=119) & $106(89.1)$ \\
\hline Yes & $13(10.9)$ \\
\hline No & \\
\hline
\end{tabular}

Table 6: Settings and Types of Voluntary Services Offered ${ }^{a}$

\begin{tabular}{|l|r|}
\hline & $\mathbf{n}(\%)$ \\
\hline Settings for offering voluntary services & $24(20.2)$ \\
\hline Homes for the elderly & $31(26.1)$ \\
\hline Schools & $11(9.0)$ \\
\hline Training facilities e.g. gymnasium, exercise classes & $11(9.0)$ \\
\hline Children's homes & $9(7.6)$ \\
\hline Crèches & $26(21.9)$ \\
\hline Hospital and clinics & $28(23.5)$ \\
\hline Sports clubs or events & $14(11.8)$ \\
\hline Buddy system & $38(32.0)$ \\
\hline Other & \\
\hline Types of voluntary services offered & $51(42.9)$ \\
\hline Talks & $21(17.7)$ \\
\hline Exercise classes & $61(51.2)$ \\
\hline Education and information & $80(67.3)$ \\
\hline Treatments & $6(5.0)$ \\
\hline Exhibitions & $21(17.7)$ \\
\hline Gifts or donations & $43(36.1)$ \\
\hline Assessments & $7(5.9)$ \\
\hline Other & \\
\hline Number of voluntary services offered by individual & $69(58.5)$ \\
\hline 1 voluntary service & $31(26.3)$ \\
\hline 2 voluntary services & $13(11.0)$ \\
\hline 3 voluntary services & $3(2.5)$ \\
\hline 4 voluntary services & $2(1.7)$ \\
\hline 5 voluntary services & \\
\hline & \\
\hline & \\
\hline & \\
\hline & \\
\hline & \\
\hline & \\
\hline & \\
\hline
\end{tabular}

a Subjects could select more than one option. 
The basic premises of ethical behaviour underpin all six indicators of social responsibility that subjects agreed with most. These premises are justice (e.g. advocating for access for all), beneficence (e.g. ensuring that policies are in the interest of clients), non-maleficence (e.g. understanding and taking into account the complex context in which physiotherapy services are delivered and the social factors that influence each individual client) and autonomy (e.g. by respecting patients' values and experiences by acting in culturally appropriate ways). As can be expected, studies with other cadres of health workers found the same foundation for socially responsive practice (Weed and Mckeown 2003; Furier and Palmer 2010).

Regarding further understanding of what social responsibility means, few subjects included all three elements of the definition in the survey: concern for doing the right thing, working toward society's health and wellness, and building cooperative relationships with society. This less than optimal view was mirrored in the response to the APTA indicators; two thirds did not regard political activism as a socially responsible practice. Activism is often the mechanism to influence policy-makers and to achieve other aspects considered part of social responsibility. Free health services for persons with disabilities were an extension of the policy of free services for mothers and children up to six years of age, realised to a large extent through activism from Disabled People Organisations, but also health workers. Similarly, less than half of the participants in a study in Mpumalanga province selected "advocating for provision of basic needs, like housing", and "mediating between different sectors for provision of service" as physiotherapy roles at primary care level (Maleka, Franzsen and Stewart 2008:4).

Correspondingly, the proportion of respondents who reported that they had given individual assessments and treatments as part of volunteering are more than the combined proportion engaged with education and talks in both the current survey and the one in 2008. These findings may mean that physiotherapists in Gauteng have not sufficiently embraced a public health strategy within a primary health care approach. Primary health care underlines client empowerment through training and selfresponsibility for wellness, and public health puts emphasis on preventing injuries and disease at community level rather than on treatment of conditions once they occur.

As in 2008 (SASP) the settings where voluntary work is done is a mix of community and clinically-based settings with the most prevalent ones being schools, old age homes, clinics, hospitals and sports clubs. Unfortunately, similar international surveys could not be found. The current study confirms the established commitment of Gauteng physiotherapists to pro bono work.

The proportion involved in the "buddy"-support system for community physiotherapist was $35 \%$ of the current sample, compared to six per cent in 2008. Two explanations are put forward for this increase. Either Gauteng physiotherapists are more involved in mentoring young colleagues than the country as a whole, or the overall number of physiotherapists involved in mentoring young colleagues has increased. This possible increase may be due to more awareness about the scheme.

The mainly positive impact on the attitudes, because of the compulsory community year, is encouraging. Through this servicenewly-graduated physiotherapists contribute to more accessible health care in South Africa. Although young doctors had serious complaints about health management, they also tended to find the compulsory year rewarding (Reid 2001). The WHO (2010, pp. 25, 26) advocates for mandatory service as one strategy to improve access to health in rural and remote areas. ${ }^{2}$ Such schemes vary from one to nine years, and have been implemented, now or previously, in 70 countries. Also, rural placements during undergraduate training can significantly increase medical students' level of social responsibility towards the rural population (Shannon et al. 2005). ${ }^{1} \mathrm{~A}$ reason for this effect may be that students are exposed to the real needs and conditions of clients in their respective communities during these placements.

Likewise, the age group below 35 years tended to be keener towards social responsible practice than other age groups. This fact may be explained thereby that themes such as the social determinants of health and professional issues have received increasing attention in curricula at South African universities over the last decade. The amount of community-based training has also increased; supporting evidence ${ }^{1}$ that suitable training is successful in retaining health workers in resource-poorer communities, like those in rural and remote areas (Kaye et al. 2010; Strasser and Neusy 2010).

\section{Limitations}

Due to the nature of a quantitative survey, only a superficial perspective of how the concept is seen by physiotherapists was reached. Also, the questionnaire asked proportionally too many questions about volunteerism, which is rather a characteristic of altruism than of social responsibility.

Non-responders could not be compared to the sample as similar demographic information was not readily available. Findings may therefore be an overestimate of importance of social responsibility, as those who were not interested probably did not participate. Another limitation is that during analysis, the responses could not fully be categorised into private or state work settings, as the subjects were not asked to specify the sector when selecting rehabilitation or sport centres as a work facility.

Furthermore, the findings do not reflect the views of all the physiotherapists in the Gauteng Province, as only members of the SASP were invited to participate. The article also does not do justice to the actions already taken by the professional society, and by other groups to which physiotherapists may belong, like Equinet.

2 Level B and C evidence on the Sacket hierarchy of evidence. 


\section{RECOMMENDATIONS}

The article gives a point of departure to start the debate on what social responsibility means to physiotherapists in the South African context. Different subgroups have unique perspectives, and these views need to be further clarified and incorporated into practice. For example, what does social responsibility entails for managers in the public service and private practice owners in terms of fair employment practices, and for educators in terms of what and how they teach and research; not to forget the outlook of clients.

Another field to explore is compulsory community service. In this study it had a positive impact on most newly graduated physiotherapists. The reasons for this positive influence need to be investigated and strengthened in practice.

Different structures would also make different contributions. The SASP as a unique stakeholder has gained momentum in its efforts to facilitate social responsibility within the profession. Policy statements like the Code of Conduct and Standards of Practice could be further implemented and monitored. The Portfolio Committee for Transformation has a prominent role to play in this regard. The newsletter, "Hands-on", could continue to highlight national and international health issues. The HPCSA could set standards on the proportion of students that needs to be recruited from rural and remote areas.

Many of the facets of social responsibility measured in this study can best be done in alliance, e.g. advocacy, influencing health policy and promoting economic efficiency. To make oneself available as a committee member at an SASP branch or at national level is a practical way to make a contribution to the betterment of the profession and society. One respondent aptly wrote: "volunteer work is not within the scope of physiotherapy." APTA would agree. It classifies pro-bono work under altruism and not social responsibility (APTA 2004). But semantics is not all important. We trust that the manuscript re-emphasised alternative ways to volunteering in which a physiotherapist can be socially responsible.

\section{CONCLUSION}

Physiotherapists in Gauteng Province have a positive view on social responsibility as defined in the study and consider it obligatory not only from the point of view of society, but also to their profession. However, they are socially responsive through pro-bono and other volunteer activities. Scope for broader understanding of the concept of social responsibility exists.

\section{ACKNOWLEDGEMENTS}

The researchers would like to thank Mrs J Mothabeng, Department of Physiotherapy, UP; Mrs M Fourie, the President, and Mr D Bührs for critically reading the manuscript; Mrs M Smith, the ex-Office Manager, and other staff at the SASP Head Office for assistance with distribution of the survey and information about the gender spread of the members; the persons who assisted with translation and finally, the participants, for their contribution.

\section{REFERENCES}

American Physical Therapy Association (APTA) 2004 Professionalism in physical therapy: core values. Available from: <http://www.apta.org/AM/ Template.cfm?Section $=$ Professionalism 1 \& T EMPLATE $=/$ CM $/$ ContentDisplay. cfm\&CONTENTID $=41460>$ [Accessed: 19 March 2010]

CSDH 2008 Closing the gap in a generation: health equity through action on the social determinants of health. Final Report of the Commission on Social Determinants of Health. World Health Organization, Genève. Available from: <http:// www.who.int/ social_determinants/ thecommission/ finalreport/en/index.htm> 2008 [Accessed 18 October 2010]

Dharamsi S, Pratt DD and MacEntee MI 2007 How dentists account for social responsibility: economic imperatives and professional obligations. Journal of Dental Education 71:1583-1592

Fan W and Yan Z 2010 Factors affecting response rates of the web survey: a systematic review. Computers in Human Behavior 26:132-139

Fricke M 2005 Primary health care: Evolving opportunities. Developed for Manitoba Branch of the Canadian Physiotherapy Association, the College of Physiotherapists of Manitoba and the Department of Physical Therapy, School of
Medical Rehabilitation, University of Manitoba. Availablefrom:http:/www.umanitoba.ca/faculties/ medicine/units/medrehab/media/pt_primary_care. pdf [Accessed: 3 February 2010]

Furier JS and Palmer VJ 2010 The ethics of everyday practice in primary medical care: responding to social health inequities. Philosophy, Ethics, and Humanities in Medicine 5:6 $<$ http://www.peh-med.com/content/5/1/6> [Accessed: 12 September 2010]

Kaye DK and Mwanika A, Sewankambo N 2010 Influence of the training experience of Makerere University medical and nursing graduates on willingness and competence to work in rural health facilities. Rural and Remote Health 10 (1372):1-8

Maleka D, Franzsen D, Stewart A 2008 Physiotherapy services required at primary health care level in Gauteng and Limpopo provinces (Service provider's perspective: physiotherapists/ assistants). South African Journal of Physiotherapy 64(1):2-7

Reid SJ 2001 Compulsory medical service for doctors in South Africa: an evaluation of the first year. South African Medical Journal 91(4):329-335

Shannon C, Baker H, Jackson J, Roy A, Heady H and Gunel E 2005 Evaluation of a required statewide interdisciplinary rural health education program: student attitudes, career intents and perceived quality. Education for Health: Change in Learning and Practice 18:395-404

South African Society of Physiotherapy (SASP) 2008 / 2009 Annual Report. pp. 4, 6 Available from: $<$ http://www.physiosa.org.za/?q=annualreview $>$ [Accessed: 19 January 2010]

Strasser R and Neusy AJ 2010 Context counts: training health workers in and for rural and remote areas. Bulletin of the World Health Organization. WHO, Genève

Witt LA and Silver NC 1994 The effects of social responsibility and satisfaction on extrarole beha viors. Basic and Applied Social Psychology 15:329-338

World Health Organization (WHO) 2008 World Health Report 2008. Primary health care: now more than ever. WHO, Genève

WHO 2010 Increasing access to health workers in remote and rural areas through improved retention: global policy recommendations. WHO, Genève

Weed DL and Mckeown RE 2003 Science and social responsibility in public health. Environmental Health Perspectives 111(14):1804-1808 